\title{
Baseline sensitivity and resistance risk assessment of Valsa mali to pyraclostrobin
}

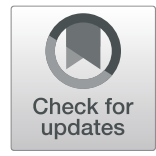

\author{
Hao Feng ${ }^{\dagger}$, Shuai Wang ${ }^{\dagger}$, Zhaoyang Liu, Jianqiang Miao, Mingxia Zhou and Lili Huang ${ }^{*}$ (D)
}

\begin{abstract}
Pyraclostrobin, a quinone outside inhibitor (Qol) fungicide, has been registered to control apple tree Valsa canker (AVC) caused by Valsa mali in China. However, there is no data available regarding the resistance risk of $\mathrm{V}$. mali to pyraclostrobin. In this study, the sensitivities of $120 \mathrm{~V}$. mali isolates to pyraclostrobin were detected. The isolates were collected from apple orchards with no application of pyraclostrob at six provinces in China during 2013-2015, and showed similar sensitivity to pyraclostrobin. The $\mathrm{EC}_{50}$ values of these $120 \mathrm{~V}$. mali isolates to pyraclostrobin ranged from 0.0014 to $0.0240 \mathrm{\mu g} / \mathrm{mL}$, indicating an excellent inhibitory efficacy of pyraclostrobin to the pathogen. The $\mathrm{EC}_{50}$ values were distributed as a unimodal curve with a mean value of $0.0091 \mu \mathrm{g} / \mathrm{mL}$, and the mean $\mathrm{EC}_{50}$ displayed correlation with geographic location. Meanwhile, three pyraclostrobin-resistant mutants (PR mutants) of $V$. mali were obtained using fungicide adaption method, with a resistance factor (RF) of 41.0, 56.8 and 22.0, respectively. The mutants showed a stable resistance to pyraclostrobin after 10 transfers on pyraclostrobin-free medium. Comparing with the corresponding parental isolates, the hyphal growth, mycelial dry weight and pathogenicity of PR mutants were significantly reduced, but the number of propagules showed no significant difference. More importantly, no cross-resistance of PR mutants to pyraclostrobin, tebuconazole, difenoconazole, imazalil and thiophanate-methyl was detected. In conclusion, V. mali showed a moderate risk to pyraclostrobin, and pyraclostrobin could be used as an alternative fungicide to control AVC in the field in China.
\end{abstract}

Keywords: Valsa Mali, Pyraclostrobin, Baseline sensitivity, Resistant risk

\section{Background}

The apple tree Valsa canker (AVC), caused by Valsa mali, is the most serious disease of apple tree in Asia, especially in China (Abe et al. 2007; Suzaki 2008; Wang et al. 2011, 2014; Li et al. 2013). Shaving diseased bark tissues and spraying fungicide on the wound were commonly used to control AVC. However, it is very difficult to cure the canker, because the pathogen could penetrate deep into the xylem (Ke et al. 2013). Meanwhile, this method also leads to the weakening of trees, making the tree more susceptible to the disease. Thus, how to inhibit the penetration of pathogen spores is the key for disease prevention. In 2013, annual dissemination of the pathogen in the field was studied systematically, and the

\footnotetext{
* Correspondence: huanglili@nwsuaf.edu.cn

${ }^{\dagger}$ Hao Feng and Shuai Wang contributed equally to this work.

State Key Laboratory of Crop Stress Biology for Arid Areas and College of

Plant Protection, Northwest A\&F University, Yangling 712100, Shaanxi, China
}

peak period of pathogen dissemination was found to be from bud stage to young fruit stage of apple tree $(\mathrm{Du}$ et al. 2013). Once pathogen spores colonize on the bark of apple tree, they then penetrate into bark tissues through lenticels, cracks, injuries, etc. (Ke et al. 2013). There is a latent period from pathogen colonizing in superficial tissues to entering into interior tissues, and the length of this latent period depends on the tree vigor (Meng et al. 2019). According to the annual dissemination and main penetration pathways of the pathogen, a prevention technology was developed and confirmed to be effective to prevent AVC by spraying fungicides or biological agents onto the bark surface for two times during June to August ( $\mathrm{Li}$ et al. 2016). Thus, it is very important to select the appropriate and effective agents. Based on the information from China Pesticide Information Network (http://www.chinapesticide.org.cn/ywb/ index.jhtml), more than 20 kinds of chemical agents

(C) The Author(s). 2020 Open Access This article is licensed under a Creative Commons Attribution 4.0 International License, which permits use, sharing, adaptation, distribution and reproduction in any medium or format, as long as you give appropriate credit to the original author(s) and the source, provide a link to the Creative Commons licence, and indicate if changes were made. The images or other third party material in this article are included in the article's Creative Commons licence, unless indicated otherwise in a credit line to the material. If material is not included in the article's Creative Commons licence and your intended use is not permitted by statutory regulation or exceeds the permitted use, you will need to obtain permission directly from the copyright holder. To view a copy of this licence, visit http://creativecommons.org/licenses/by/4.0/. 
were registered to control AVC. Among them, the benzimidazole fungicide thiophanate-methyl was widely used in the past few years, which was effective in preventing infection of $V$. mali but showed little capacity in inhibiting the expansion of lesions (Tamura and Saito 1982). In recent years, the demethylation inhibitors, tebuconazole and difenoconazole, have been demonstrated to be very effective against $V$. mali and have become alternative fungicides to control AVC (Chen et al. 2009; Ma et al. 2012; Guo et al. 2015; Gao et al. 2017). Long-term use of single fungicide increased the risk of fungicide resistance. Although no fungicide-resistant strain of $V$. mali was found, the sensitivity of $V$. mali to difenoconazole has declined (Liu et al. 2019). Thus, it is urgent to find more fungicides with high efficiency in the control of AVC.

In early 2000s, a new fungicide, pyraclostrobin, belonging to quinone outside inhibitor (QoI) class, was developed by BASF Corporation, which was found to be preventive, curative, and eradicative against many plant diseases by inhibiting spore germination, mycelial growth, and sporulation of the target pathogenic fungi (Bartlett et al. 2002; Liang et al. 2015). However, QoIs are classified as high risk fungicides for triggering fungal resistance by Fungicide Resistance Action Committee (FRAC). In the past years, some populations of Botrytis cinerea have been found to be resistant to pyraclostrobin (Kim and Xiao 2011; Fernández-Ortuño et al. 2012). Meanwhile, isolates of Alternaria alternata have also showed resistance to pyraclostrobin (Avenot and Michailides 2015; Fan et al. 2015).

Pyraclostrobin has been confirmed to be effective against $V$. mali in laboratory test (Ma et al. 2012; Guo et al. 2015). However, the resistance risk of $V$. mali to pyraclostrobin is still largely unknown. In this study, the baseline sensitivity to pyraclostrobin of $120 \mathrm{~V}$. mali stains from China was determined. Furthermore, pyraclostrobin-resistant mutants (PR mutants) of $V$. mali were obtained by fungicide adaption. Fitness of these resistant mutants in vitro and their cross-resistance to pyraclostrobin and other fungicides were subsequently investigated. The results will provide important guidance for scientific and rational use of pyraclostrobin in AVC control.

\section{Results}

\section{Baseline sensitivity of $V$. mali to pyraclostrobin}

SHAM was often used to inhibit the alternative oxidase (AOX) in determination of the sensitivity of a pathogen to QoI fungicide. Thus, we firstly evaluated its effects on the mycelial growth of eight randomly selected isolates with different genetic background. The results showed that SHAM at $100 \mu \mathrm{g} / \mathrm{mL}$ had no effect on the $\mathrm{EC}_{50}$ value of $V$. mali to pyraclostrobinin on AEA medium, whereas had significant inhibitory activity against the mycelial growth of V. mali (Additional file 1: Table S1). Thus, AEA medium without exogenous SHAM was used to detect the baseline sensitivity of $V$. mali to pyraclostrobin. The $\mathrm{EC}_{50}$ values of the corresponding isolates to pyraclostrobin ranged from 0.0014 to $0.0240 \mu \mathrm{g} / \mathrm{mL}$, with a mean value of $0.0091 \mu \mathrm{g} / \mathrm{mL}$, and the ratio of the maximum to the minimum $\mathrm{EC}_{50}$ values was 17.5 (Additional file 2: Table S2). The frequency distribution of the $\mathrm{EC}_{50}$ values of these $V$. mali isolates showed a unimodal curve with a positive skew (Fig. 1). Therefore, no resistance was observed in the field isolates of $V$. mali that we collected. However, the mean $\mathrm{EC}_{50}$ values of $V$. mali strains collected from different geographic locations were significantly different. For example, the mean $\mathrm{EC}_{50}$ values of strains from Liaoning were highest $(0.0128 \pm 0.0061 \mu \mathrm{g} / \mathrm{mL})$, while from Xinjiang were lowest $(0.0040 \pm 0.0015 \mu \mathrm{g} / \mathrm{mL})$ (Table 1$)$.

\section{Generation of pyraclostrobin-resistant (PR) mutants of $V$. mali and the resistance stability of mutants}

Two PR mutants (XJVM001R1 and XJVM001R2) were obtained from the parental isolate XJVM001; one PR mutant (972R) was obtained from the parental isolate 972. These three resistant mutants exhibited resistance factor (RF) values of 41.0, 56.8 and 22.0, respectively (Table 2). After 10 transfers on pyraclostrobin-free PDA, XJVM001R1 and XJVM001R2 still kept a moderate resistance to pyraclostrobin, with RF values of 33.9 and 52.5 , respectively. However, the RF value of $972 \mathrm{R}$ declined from 22.0 to 11.7. Thus, the resistances of XJVM001R1 and XJVM001R2 to pyraclostrobin were more stable than that of $972 R$.

Characterization of PR mutants and their parental isolates Compared to their parental isolates, all PR mutants had a smaller colony diameter and a reduced mycelial dry weight. There were no significant differences in propagule number between PR mutants and their parental isolates. However, the virulence of PR mutants was lower than that of their parental isolates (Fig. 2 and Table 3). The $\mathrm{EC}_{50}$ values of PR mutants to pyraclostrobin were significantly higher than that of their parental isolates. More importantly, the sensitivity of PR mutants and their parental isolates to pyraclostrobin was not correlated with the sensitivity to tebuconazole, difenoconazole, imazalil, and thiophanate-methyl (Fig. 3 and Table 4). In other words, no cross-resistance in PR mutants to pyraclostrobin, tebuconazole, difenoconazole, imazalil and thiophanate-methyl was detected.

\section{Discussion}

It is of great importance to establish baseline sensitivity data of a phytopathogenic fungus to a fungicide, as such 


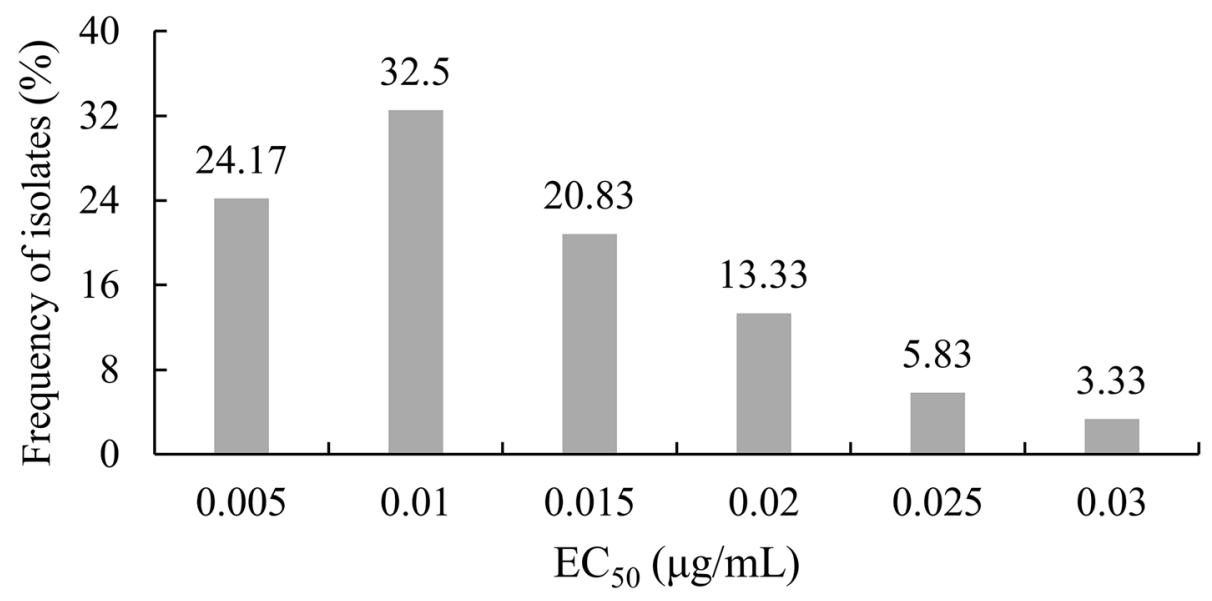

Fig. 1 Frequency distribution of the effective concentrations of pyraclostrobin for $50 \%$ inhibition of mycelial growth (EC 50 ) of Valsa mali. In total, $120 \mathrm{~V}$. mali isolates were collected from apple orchards with no history of pyraclostrob application in China. Values on the bar show frequencies of isolates with corresponding $\mathrm{EC}_{50}$ values

data are useful to evaluate the risk of resistance development in sensitive populations of the fungi, and meanwhile provide evidence to suggest future methods for control of fungicide-resistant mutants (Zhang et al. 2015). In this study, the baseline sensitivity and resistance risk of $V$. mali populations in China to pyraclostrobin were reported.

The alternative oxidase (AOX) provides an alternative route for respiration and it will usually be activated after QoIs inhibit mitochondrial respiration in fungi by binding to the Qo site of the cytochrome bc1 complex and blocking electron transfer (Piccirillo et al. 2018). SHAM, an AOX inhibitor, is commonly added into culture media to suppress alternative respiration (Mizutani et al. 1995). In previous study, SHAM was confirmed to possess different effects on the sensitivity of pathogens to QoI fungicide (Di et al. 2016). Thus, it is necessary to firstly detect the effect of SHAM to the mycelial growth of $V$. mali in this study. According to the results we

Table 1 Sensitivity to pyraclostrobin of Valsa mali field isolates from different locations in China

\begin{tabular}{|c|c|c|c|}
\hline \multirow{2}{*}{$\begin{array}{l}\text { Sampling } \\
\text { site }\end{array}$} & \multirow{2}{*}{$\begin{array}{l}\text { Number } \\
\text { of } \\
\text { isolates }\end{array}$} & \multicolumn{2}{|l|}{$\mathrm{EC}_{50}(\mu \mathrm{g} / \mathrm{mL})$} \\
\hline & & Range & Mean \\
\hline Liaoning & 10 & $0.0055-0.0234$ & $0.0128 \pm 0.0061 \mathrm{a}$ \\
\hline Shandong & 17 & $0.0041-0.0240$ & $0.0110 \pm 0.0058 \mathrm{ab}$ \\
\hline Gansu & 15 & $0.0040-0.0184$ & $0.0105 \pm 0.0044 a b$ \\
\hline Shanxi & 36 & $0.0014-0.0227$ & $0.0094 \pm 0.0057 \mathrm{ab}$ \\
\hline Shaanxi & 31 & $0.0024-0.0232$ & $0.0076 \pm 0.0050 \mathrm{bc}$ \\
\hline Xinjiang & 11 & $0.0022-0.0070$ & $0.0040 \pm 0.0015 c$ \\
\hline
\end{tabular}

obtained, SHAM $(100 \mu \mathrm{g} / \mathrm{mL})$ has significant inhibitory activity against the mycelial growth of $V$. mali, but does not affect the $\mathrm{EC}_{50}$ value of $V$. mali to pyraclostrobin. So, we determined the baseline sensitivity of $V$. mali populations to pyraclostrobin by not amending the medium with SHAM. The results showed that no pyraclostrobin-resistant $V$. mali isolate was detected. This sensitivity baseline could be used for monitoring any future sensitivity shifts to pyraclostrobin in the field populations of $V$. mali. Meanwhile, the mean $\mathrm{EC}_{50}$ values of $V$. mali isolates to pyraclostrobin were different. Similar result was also observed when the sensitivity of Rhizoctonia cerealis isolates collected from different geographic location to trifluzamide was detected (Qi et al. 2014). It may be related to the natural differences of the strains in different regions, the physiological differences in the strains themselves, as well as the population structure of the strains of $V$. mali.

Fungal pathogens may develop resistance to different fungicides under certain selection pressures or under conditions of adversity. Resistance to QoI fungicides has been reported in a broad range of plant pathogenic fungi such as Plasmopara viticola (Wong and Wilcox 2000), Venturia inaequalis (Steinfeld et al. 2001) and Magnaporthe grisea (Avila-Adame and Koller 2003). In this study, 14 wild parental isolates of $V$. mali were randomly selected to produce PR mutants by repeated exposure to pyraclostrobin, and three resistant mutants were obtained. The resistance levels of two PR mutants were still stable over ten generations. The failure in using other parental isolates to generate stable resistant mutants might be related to the genetic variation among different strains (Pang et al. 2013).

Changes in biological traits could affect the competitiveness of resistant mutants and sensitive strains in 
Table 2 Level and stability of pyraclostrobin resistance in PR mutants and their parental isolates of Valsa mali

\begin{tabular}{|c|c|c|c|c|c|}
\hline \multirow[t]{2}{*}{ Isolate } & \multirow[t]{2}{*}{ Origin } & \multicolumn{2}{|l|}{$\mathrm{EC}_{50}(\mu \mathrm{g} / \mathrm{mL})$} & \multicolumn{2}{|l|}{ RF } \\
\hline & & 1st generation & 10th generation & 1st generation & 10th generation \\
\hline XJVM001 & Parent & $0.0033 d$ & $0.0030 \mathrm{~d}$ & - & - \\
\hline XJVM001R1 & PR mutant & $0.1350 \mathrm{~b}$ & $0.1020 \mathrm{~b}$ & 41.0 & 33.9 \\
\hline XJVM001R2 & PR mutant & $0.1870 \mathrm{a}$ & $0.1580 \mathrm{a}$ & 56.8 & 52.5 \\
\hline 972 & Parent & $0.0051 \mathrm{~d}$ & $0.0049 \mathrm{~d}$ & - & - \\
\hline $972 R$ & PR mutant & $0.1120 c$ & $0.0575 c$ & 22.0 & 11.7 \\
\hline
\end{tabular}

$\mathrm{EC}_{50}=$ effective concentration for $50 \%$ inhibition of mycelial growth; $\mathrm{RF}$ (resistance factor) $=\mathrm{EC}_{50}$ for the resistant mutant/EC ${ }_{50}$ for the sensitive parental isolate; $\mathrm{PR}$ mutants were obtained by growing parental isolates on pyraclostrobin-amended medium. PR mutants are listed below their respective parents. Multiple range test was used to compare $\mathrm{EC}_{50}$ values using Fisher's least significant difference test. Values followed by different letters are significantly different at $P<0.05$

nature (Ziogas et al. 2003). Thus, biological fitness parameters are considered to be important factors that affect the formation of a fungicide-resistant population of fungal pathogens in the field (Zhang et al. 2014). The pyraclostrobin-resistant strains of $B$. cinerea showed decreased sporulation rate, spore germination rate and sclerotial production (Markoglou et al. 2006). Meanwhile, the resistance change of $A$. alternate to pyraclostrobin did not affect the mycelial growth, conidial germination, and conidial production, but the resistant strains showed similar or increased virulence compared to that of sensitive strains (Vega and Dewdney 2014). In this study, the mycelial growth, mycelial dry weight and pathogenicity of resistant mutants were reduced compared with those of their sensitive parental strains, but there was no significant difference in the propagules number. The reduced pathogenicity of resistant mutants might be related to their decreased growth.

Clarifying cross-resistance of a pathogen to different fungicides will help to provide a theoretical basis for scientific application of fungicides on the control of the pathogen. Based on our results, no cross-resistance was detected among pyraclostrobin, tebuconazole, difenoconazole, imazalil and thiophanate-methyl in PR mutants. Due to the low fitness of PR mutants and lack of crossresistance with other fungicides, we concluded that the resistant risk of $V$. mali to pyraclostrobin was at a lowto-moderate level. To avoid the generation of

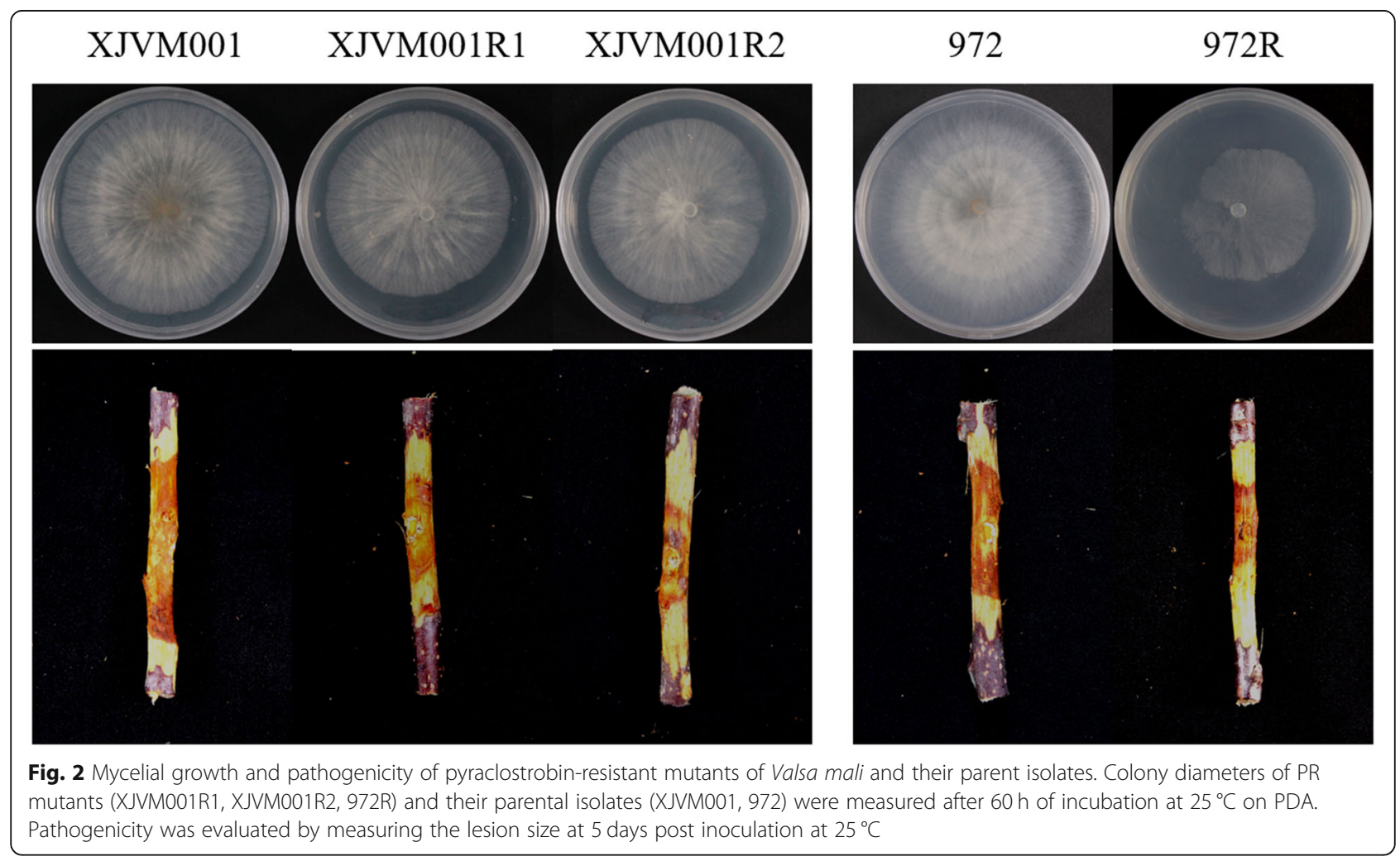


Table 3 Comparison of mycelial growth, number of propagules, dry weight of mycelia and pathogenicity between PR mutants and their parental isolates

\begin{tabular}{lllll}
\hline Isolate & Colony diameter $(\mathbf{m m})$ & $\begin{array}{l}\text { Number of propagules } \\
\text { per plate }\end{array}$ & Dry weight of mycelia (g /flask) & Lesion length on twigs (mm) \\
\hline XJVM001 & $72.2 \mathrm{~b}$ & $267.8 \mathrm{~b}$ & $0.3071 \mathrm{~b}$ & $40.3 \mathrm{a}$ \\
XJVM001R1 & $62.9 \mathrm{C}$ & $263.6 \mathrm{~b}$ & $0.2878 \mathrm{c}$ & $29.2 \mathrm{~b}$ \\
XJVM001R2 & $61.8 \mathrm{C}$ & $265.3 \mathrm{~b}$ & $0.2882 \mathrm{c}$ & $28.3 \mathrm{~b}$ \\
972 & $78.6 \mathrm{a}$ & $311.1 \mathrm{a}$ & $0.3129 \mathrm{a}$ & $36.5 \mathrm{a}$ \\
$972 \mathrm{R}$ & $47.6 \mathrm{~d}$ & $314.2 \mathrm{a}$ & $0.2792 \mathrm{~d}$ & $25.6 \mathrm{~b}$ \\
\hline
\end{tabular}

Multiple range test was used to compare colony diameter, propagule number, dry weight and lesion length using Fisher's least significant difference test. Values followed by different letters are significantly different at $P<0.05$

pyraclostrobin resistance in $V$. mali, we suggest that fungicides with different mechanisms should be used alternately. Otherwise, applying pyraclostrobin in mixtures with multisite or non-cross-resistant fungicides may be adopted for control of AVC and fungicide resistance management of $V$. mali.

\section{Conclusions}

In this study, baseline sensitivity of $V$. mali to pyraclostrobin was established and the efficiency of pyraclostrobin against $V$. mali was subsequently evaluated. All the $120 \mathrm{~V}$. mali isolates showed similar and high sensitivity to pyraclostrobin. Meanwhile, the resistance risk of these $V$. mali isolates to pyraclostrobin was evaluated, and no cross-resistance between pyraclostrobin and other fungicides including tebuconazole, difenoconazole, imazalil and thiophanate-methyl was detected in PR mutants. Thus, pyraclostrobin could be used as an alternative fungicide to control AVC in China. Meanwhile, V. mali showed a moderated risk to pyraclostrobin, and the corresponding resistance management strategies should also be considered. These results will lay a foundation for the scientific application of pyraclostrobin in the field.

\section{Methods}

Pathogen isolates, culture media and fungicides

A total of 120 isolates of $\mathrm{V}$. mali were tested in this study (Additional file 3: Table S3), which were collected
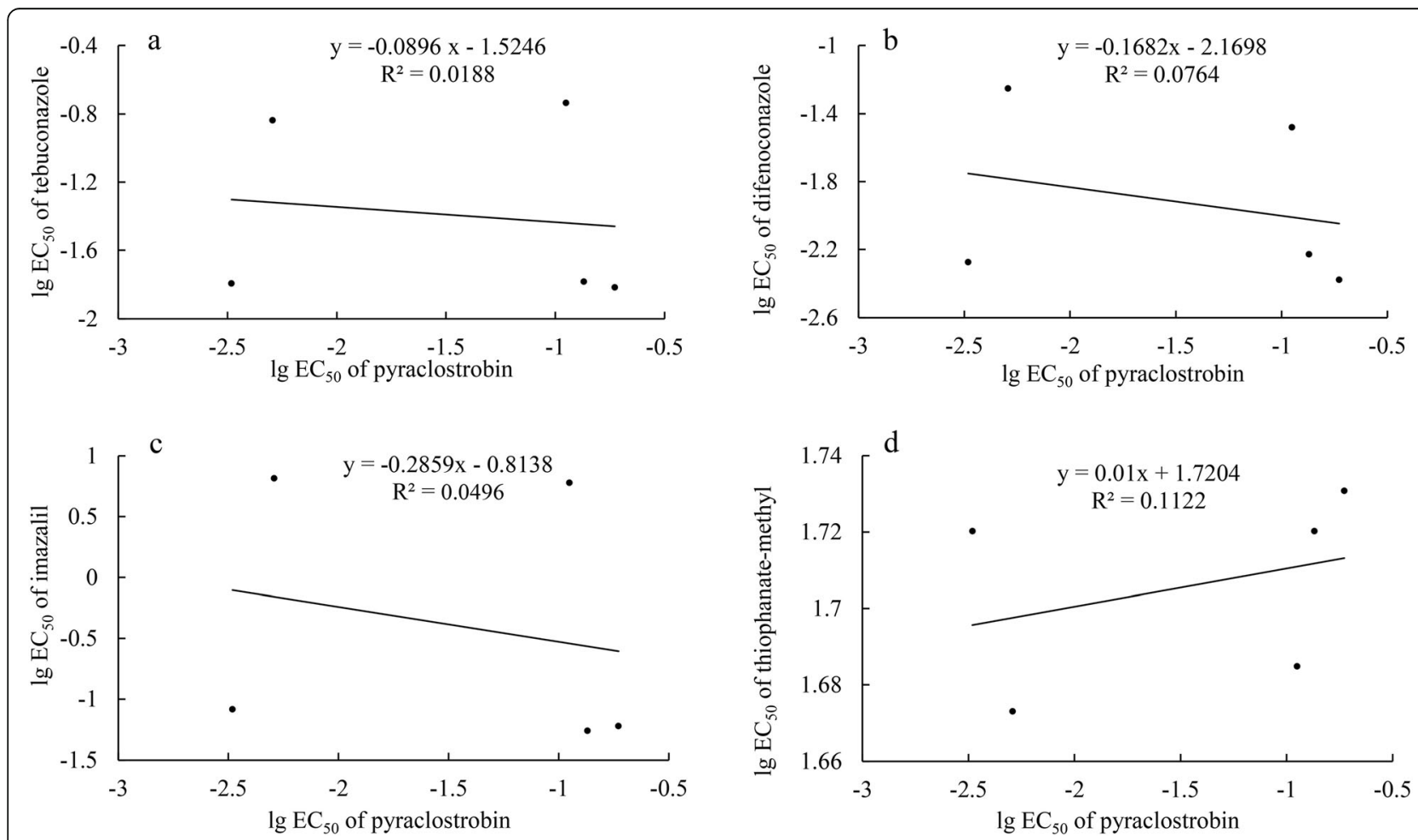

Fig. 3 Cross-resistance assays between pyraclostrobin and other four fungicides in Valsa mali. a Cross-resistance assay between pyraclostrobin and tebuconazole. $\mathbf{b}$ Cross-resistance assay between pyraclostrobin and difenoconazole. $\mathbf{c}$ Cross-resistance assay between pyraclostrobin and imazalil. $\mathbf{d}$ cross-resistance between pyraclostrobin and thiophanate-methyl 
Table 4 Sensitivities of pyraclostrobin-sensitive and pyraclostrobin-resistant mutants of Valsa mali to different fungicides

\begin{tabular}{llllll}
\hline Isolate & $\mathrm{EC}_{\mathbf{5 0}}(\boldsymbol{\mu g} / \mathbf{m L})$ & & & \\
\cline { 2 - 6 } & Pyraclostrobin & Tebuconazole & Difenoconazole & Imazalil & Thiophanate-methyl \\
\hline XJVM001 & 0.00329 & 0.0161 & 0.00531 & 0.0825 & 52.5 \\
XJVM001R1 & 0.13500 & 0.0165 & 0.00586 & 0.0548 & 52.5 \\
XJVM001R2 & 0.18700 & 0.0153 & 0.00418 & 0.0599 & 53.8 \\
972 & 0.00508 & 0.1450 & 0.05570 & 6.5200 & 47.1 \\
$972 R$ & 0.11200 & 0.1830 & 0.03300 & 5.9900 & 48.4 \\
\hline
\end{tabular}

from infected apple trees in orchards with no application of pyraclostrobin at different geographic regions of China (Liaoning, Shandong, Gansu, Shanxi, Shaanxi, and Xinjiang) during 2013-2015. All the isolates were maintained on potato dextrose agar (PDA) medium at $4{ }^{\circ} \mathrm{C}$. Alkyl ester agar (AEA) medium was used to detect the sensitivity of $V$. mali to pyraclostrobin. PDA medium was used to detect the sensitivity of the pathogen to other fungicides. PDB medium was used to culture strains of $V$. mali. All fungicides used were technical-grade products, including pyraclostrobin (97.5\% a.i.; Xi'an Hytech Agrochemicals Co., Ltd., China), tebuconazole (97\% a.i.; Jiangsu Flag Chemical Industry Co., Ltd., China), difenoconazole (95\% a.i.; Xi'an Hytech Agrochemicals Co., Ltd.), imazalil (98\% a.i.; Anhui Guangxin Agrochemical Co., Ltd., China), and thiophanate-methyl (97\% a.i.; Anhui Huaxing Chemical Industry Co., Ltd., China). Pyraclostrobin, tebuconazole, difenoconazole and imazalil were respectively dissolved in acetone to produce a stock solution containing $10 \mathrm{mg} / \mathrm{mL}$ of the active ingredient. Tiophanate-methyl was dissolved in acetone and then diluted with $0.1 \%$ Tween-20 to produce a stock solution containing $3.2 \mathrm{mg} /$ $\mathrm{mL}$ of the active ingredient. Fungicide stock solution was then stored in the dark at $4{ }^{\circ} \mathrm{C}$ until used.

\section{Baseline sensitivity of $V$. mali isolates to pyraclostrobin} The sensitivities of 120 isolates of $V$. mali to pyraclostrobin were determined by measuring mycelial growth on agar plates. Mycelial plugs ( $5 \mathrm{~mm}$ in diameter) from the edge of a 3-day-old colony were transferred to a series of AEA plates amended with increasing concentrations of pyraclostrobin $(0,0.000625,0.0025,0.01,0.025,0.04$, $0.16,0.64$, and $2.56 \mu \mathrm{g} / \mathrm{mL}$ ), and the final concentration of acetone in the medium was standardized at $0.1 \%(\mathrm{v} /$ v). Plates without pyraclostrobin were used as control. The plates were incubated at $25^{\circ} \mathrm{C}$ for three days in a growth chamber. For each plate, the $\mathrm{EC}_{50}$ value was calculated by measuring the average colony diameter and regressing the percentage growth inhibition against the $\log$ of fungicide concentration. The experiment was repeated twice with three replicates for each treatment.

\section{Generation of PR mutants of $V$. mali}

Fourteen isolates (03-8, XJVM001, XJVM006, 878, 881, 889, 891, 893, 902, 910,972, 980, 982 and 985) of $V$. mali were randomly selected to generate PR mutants. Fresh mycelial plugs from colony margins were transferred to AEA plates (seven plugs per plate) containing pyraclostrobin of $80 \mu \mathrm{g} / \mathrm{mL}$. After incubation at $25^{\circ} \mathrm{C}$ for two weeks, any fast-growing sectors from the otherwise restricted colonies were transferred to a series of AEA plates amended with increasing concentrations of pyraclostrobin (100, 200 and $500 \mu \mathrm{g} / \mathrm{mL}$ ) (Wang et al. 2015).

\section{Resistance level and stability of PR mutants}

To determine the resistance level of PR mutants to pyraclostrobin, mycelial plugs of the mutants were placed on AEA plates amended with $0,0.002,0.02,0.2,2,20$, and $200 \mu \mathrm{g} /$ $\mathrm{mL}$ of pyraclostrobin. The $\mathrm{EC}_{50}$ values were calculated by regressing the percentage growth inhibition against the log of fungicide concentration. The level of fungicide resistance, termed as resistance factor (RF), was equal to the $\mathrm{EC}_{50}$ value

Table 5 Fungicides and concentrations used to analyze cross-resistance between pyraclostrob and other fungicides in pyraclostrobin-sensitive and pyraclostrobin-resistant Valsa mali isolates

\begin{tabular}{|c|c|c|c|c|c|}
\hline \multirow{2}{*}{$\begin{array}{l}\text { V. mali } \\
\text { strains }\end{array}$} & \multicolumn{5}{|c|}{ Fungicides \& Concentrations $(\mu \mathrm{g} / \mathrm{mL}$ ) } \\
\hline & Pyraclostrobin & Tebuconazole & Difenoconazole & Imazalil & $\begin{array}{l}\text { Thiophanate- } \\
\text { methyl }\end{array}$ \\
\hline XJVM001 & $0.000625,0.0025,0.01,0.04,0.16$ & $0.005,0.01,0.02,0.04,0.08$ & $0.002,0.004,0.008,0.016,0.032$ & $0.025,0.05,0.1,0.2,0.4$ & $40,60,80,120,240$ \\
\hline XJVM001R1 & $0.002,0.02,0.2,2,20$ & $0.005,0.01,0.02,0.04,0.08$ & $0.002,0.004,0.008,0.016,0.032$ & $0.025,0.05,0.1,0.2,0.4$ & $40,60,80,120,240$ \\
\hline XJVM001R2 & $0.002,0.02,0.2,2,20$ & $0.005,0.01,0.02,0.04,0.08$ & $0.002,0.004,0.008,0.016,0.032$ & $0.025,0.05,0.1,0.2,0.4$ & $40,60,80,120,240$ \\
\hline 972 & $0.000625,0.0025,0.01,0.04,0.16$ & $0.05,0.1,0.2,0.4,0.8$ & $0.015,0.03,0.06,0.12,0.24$ & $2,4,8,16,32$ & $40,60,80,120,240$ \\
\hline $972 R$ & $0.002,0.02,0.2,2,20$ & $0.05,0.1,0.2,0.4,0.8$ & $0.015,0.03,0.06,0.12,0.24$ & $2,4,8,16,32$ & $40,60,80,120,240$ \\
\hline
\end{tabular}


of the resistant mutant divided by the $\mathrm{EC}_{50}$ value of the parental isolate (Wang et al. 2015). To evaluate the stability of the resistant phenotypes, the PR mutants were subjected to ten successive transfers on new fungicide-free PDA plates. The RFs at the 1st and 10th generations were determined as described by Wang et al. (2015).

\section{Hyphal growth, dry weight, propagule number, and pathogenicity of the PR mutants and their parental isolates}

Hyphal growth and propagule number of PR mutants and their parental isolates were determined on fungicide-free PDA plates. Colony diameters were measured perpendicularly after incubation at $25^{\circ} \mathrm{C}$ for $60 \mathrm{~h}$. The number of propagules was subjectively evaluated when the mutants were cultured for $25 \mathrm{~d}$ under natural light at room temperature. Moreover, five mycelial plugs taken from the colony edge of each PR mutant and parental isolate were transferred to a flask containing 100 $\mathrm{mL}$ of PDB. After $3 \mathrm{~d}$ cultivation at $25^{\circ} \mathrm{C}$ with shaking at $100 \mathrm{rpm}$, the mycelia were collected, dried $\left(56^{\circ} \mathrm{C}\right.$ for $12 \mathrm{~h}$ ), and weighed. There were three replicate plates and three replicate flasks for each isolate, and the experiment was repeated three times. The virulence of PR mutants and parental isolates was determined by a scald wounding method, which was carried out by inoculating detached twigs of Malus domestica Borkh. cv. 'Fuji' with a $5 \mathrm{~mm}$ mycelial plug derived from the margin of a young colony (Zang et al. 2007; Wei et al. 2010). After 5 $\mathrm{d}$ incubation at $25^{\circ} \mathrm{C}$, the length of each necrotic lesion was measured. Three twigs for each isolate were inoculated, and the experiment was performed three times.

\section{Cross-resistance analysis}

Pyraclostrobin-resistant and pyraclostrobin-sensitive isolates were used to assess their sensitivity to five fungicides, including pyraclostrobin, tebuconazole, difenoconazole, imazalil, and thiophanate-methyl. It was proceeded by using the same method of mycelial growth inhibition described above with fungicides at various final concentrations (Table 5). The individual $\mathrm{EC}_{50}$ values for these fungicides in all isolates were calculated. The experiment was repeated three times.

\section{Statistical analysis}

The data from different repetitions were used for statistical analysis. All statistical analysis was performed using SPSS 16.0 (Statistical Package for the Social Science, SPSS Inc., Chicago, IL). A regression equation was derived by correlating the $\log 10$ of inhibitor concentration of pyraclostrobin with the probit of inhibition percentage of average radial mycelial growth of $V$. mali, and effective concentration for $50 \%$ inhibition $\left(\mathrm{EC}_{50}\right)$ of $V$. mali was calculated from the regression equation. The
ANOVA procedure of SPSS $(P<0.05)$ was used to determine significant differences among the $\mathrm{EC}_{50}$ values.

\section{Supplementary information}

Supplementary information accompanies this paper at https://doi.org/10. 1186/s42483-020-00072-9.

Additional file 1: Table S1. Sensitivity assay of Valsa mali to pyraclostrobin in AEA medium with or without SHAM.

Additional file 2: Table S2. Sensitivity of 120 Valsa mali isolates to pyraclostrobin.

Additional file 3: Table S3. Details of 120 Valsa mali isolates used in this study.

\section{Abbreviations}

AEA: Alkyl ester agar; ANOVA: Analysis of variance; AVC: Apple Valsa canker; $\mathrm{EC}_{50}$ : Effective concentration for $50 \%$ inhibition of mycelial growth; FRAC: Fungicide Resistance Action Committee; PDA: Potato dextrose agar; PDB: Potato dextrose broth; PR: Pyraclostrobin-resistant; Qol: Quinone outside inhibitor; RF: Resistance factor; SHAM: Salicylhydroxamic acid; V. mali: Valsa mali

\section{Acknowledgements}

We thank Prof. Xili Liu and Prof. Yong Wang at Northwest A\&F University for their helpful suggestions on the manuscript.

\section{Authors' contributions}

$\mathrm{LH}$ and HF designed the research. SW, ZL and MZ performed the experiments. HF, SW and JM analyzed the data. HF and SW wrote the manuscript. All authors have read and approved the final manuscript.

\section{Funding}

This work was supported by the National Key R\&D Program of China (2016YFD0201100).

Availability of data and materials

Not applicable.

Ethics approval and consent to participate Not applicable.

Consent for publication

Not applicable.

\section{Competing interests}

The authors declare that they have no competing interests.

Received: 12 July 2020 Accepted: 9 September 2020

Published online: 05 October 2020

References

Abe K, Kotoda N, Kato H, Soejima J. Resistance sources to Valsa canker (Valsa ceratosperma) in a germplasm collection of diverse Malus species. Plant Breed. 2007;126:449-53.

Avenot HF, Michailides TJ. Detection of isolates of Alternaria alternata with multiple-resistance to fludioxonil, cyprodinil, boscalid and pyraclostrobin in California pistachio orchards. Crop Prot. 2015;78:214-21.

Avila-Adame C, Koller W. Characterization of spontaneous mutants of Magnaporthe grisea expressing stable resistance to the Qo-inhibiting fungicide azoxystrobin. Curr Genet. 2003;42:332-8.

Bartlett DW, Clough JM, Godwin JR, Hall AA, Hamer M, Parr-Dobrzanski B. The strobilurin fungicides. Pest Manag Sci. 2002;58:649-62.

Chen L, Liu JL, Si NG, Zhang LQ, Sun YJ, Lin WZ. Efficacy of SYP-3375 against apple Valsa canker. Agrochemicals. 2009;48(6):402-4 (in Chinese). https://doi. org/10.16820/j.cnki.1006-0413.2009.06.004.

Di YL, Zhu ZQ, Lu XM, Zhu FX. Baseline sensitivity and efficacy of trifloxystrobin against Sclerotinia sclerotiorum. Crop Prot. 2016;87:31-6. 
Du ZT, Li ZP, Gao XN, Huang LL, Han QM. Study on the conidia dispersal and the disease dynamics of apple tree canker caused by Valsa mali var. mali in Shaanxi. J Fruit Sci. 2013;30(5):819-22 (in Chinese). https://doi.org/10.13925/j. cnki.gsxb.2013.05.003.

Fan Z, Yang JH, Fan F, Luo CX, Schnabel G. Fitness and competitive ability of Alternaria alternata field isolates with resistance to $\mathrm{SDHI}$, Qol and MBC fungicides. Plant Dis. 2015;99:1744-50.

Fernández-Ortuño D, Chen F, Schnabel G. Resistance to pyraclostrobin and boscalid in Botrytis cinerea isolates from strawberry fields in the Carolinas. Plant Dis. 2012;96:1198-203.

Gao S, Gao XN, Feng H, Han QM, Huang LL. Effects of difenoconazole on the mycelial morphology and ultrastructure of Valsa mali. J Fruit Sci. 2017;34(10): 1323-9 (in Chinese). https://doi.org/10.13925/j.cnki.gsxb.20170121.

Guo XF, Xu BL, Han J, Xu CZ, Wang WX, Zhang SW. Control effect of 5 chemicals against apple tree canker in laboratory. Chin Agric Sci Bull. 2015;31(18):28590 (in Chinese). https://doi.org/10.11924/j.issn.1000-6850.casb15020078

Ke XW, Huang LL, Han QM, Gao XN, Kang ZS. Histological and cytological investigations of the infection and colonization of apple bark by Valsa mali var. mali. Australas Plant Pathol. 2013:42:85-93.

Kim YK, Xiao CL. Stability and fitness of pyraclostrobin- and boscalid-resistant phenotypes in field isolates of Botrytis cinerea from apple. Phytopathology. 2011;101:1385-91.

Li ZP, Gao XN, Du ZT, Hu Y, Kang ZS, Huang LL. Survey of apple Valsa canker in Weibei area of Shaanxi province. Acta Agric Boreali-Occident Sin. 2013;22(1): 174-8 (in Chinese). https://doi.org/10.7606/j.issn.1004-1389.2013.01.029.

Li ZP, Gao XN, Kang ZS, Huang LL, Fan DY, Yan X, et al. Saccharothrix yanglingensis strain Hhs.015 is a promising biocontrol agent on apple Valsa canker. Plant Dis. 2016;100(2):510-4.

Liang HJ, Di YL, Li JL, You H, Zhu FX. Baseline sensitivity of pyraclostrobin and toxicity of SHAM to Sclerotinia sclerotiorum. Plant Dis. 2015;99(2):267-73.

Liu J, Feng H, Wang S, Gao XN, Huang LL. Sensitivity of Valsa mali to difenoconazole in China. Plant Prot. 2019:45(1):170-3 (in Chinese). https://doi. org/10.16688/j.zwbh.2018119.

Ma YQ, Li JP, Wang L, Li JJ, Hui NN, Zhou TW. Inhibitory effects of five fungicides on apple tree Valsa canker. Gansu Agric Sci Technol. 2012;6:20-2 (in Chinese).

Markoglou AN, Malandrakis AA, Vitoratos AG, Ziogas BN. Characterization of laboratory mutants of Botrytis cinerea resistant to Qol fungicides. Eur J Plant Pathol. 2006:115:149-62.

Meng XL, Qi XH, Han ZY, Guo YB, Wang YN, Hu TL, et al. Latent infection of Valsa mali in the seeds, seedlings and twigs of crabapple and apple trees is a potential inoculum source of Valsa canker. Sci Rep. 2019;9:7738.

Mizutani A, Yukioka H, Tamura H, Miki N, Masuko M, Takeda R. Respiratory characteristics in Pyricularia oryzae exposed to a novel alkoxyiminoacetamide fungicide. Phytopathology. 1995;85:306-11.

Pang ZL, Shao JP, Chen L, Lu XH, Hu J, Qin ZH, et al. Resistance to the novel fungicide pyrimorph in Phytophthora capsici: risk assessment and detection of point mutations in CesA3 that confer resistance. PLoS One. 2013;8:e56513.

Piccirillo G, Carrieri R, Polizzi G, Azzaro A, Lahoz E, Fernández-Ortuño D, et al. In vitro and in vivo activity of Qol fungicides against Colletotrichum gloeosporioides causing fruit anthracnose in Citrus sinensis. Sci Hortic. 2018;236:90-5.

Qi YZ, Li HY, Su Y, Zhen WC. Sensitivity to trifluzamide and main biological characteristics of resistant mutants of Rhizoctonia cerealis. Chin J Pestic Sci. 2014;16(3):271-80 (in Chinese). https://doi.org/10.3969/j.issn.10087303.2014.03.05.

Steinfeld U, Sierotzki H, Parisi S, Poirey S, Gisi U. Sensitivity of mitochondrial respiration to different inhibitors in Venturia inaequalis. Pest Manag Sci. 2001; 57(9):787-96.

Suzaki K. Population structure of Valsa ceratosperma, causal fungus of Valsa canker, in apple and pear orchards. J Gen Plant Pathol. 2008:74:128.

Tamura O, Saito I. Histopathological changes of apple bark infected by Valsa ceratosperma (Tode ex Fr.) Maire during dormant and growing periods. Ann Phytopathol Soc Jpn. 1982;48:490-8. https://doi.org/10.3186/ jjphytopath.48.490.

Vega B, Dewdney MM. Qol-resistance stability in relation to pathogenic and saprophytic fitness components of Alternaria alternata from citrus. Plant Dis. 2014;98:1371-8

Wang XL, Wei JL, Huang LL, Kang ZS. Re-evaluation of pathogens causing Valsa canker on apple in China. Mycologia. 2011;103(2):317-24.

Wang XL, Zang R, Yin ZY, Kang ZS, Huang LL. Delimiting cryptic pathogen species causing apple Valsa canker with multilocus data. Ecol Evol. 2014;4(8): $1369-80$
Wang Y, Duan YB, Zhou MG. Molecular and biochemical characterization of boscalid resistance in laboratory mutants of Sclerotinia sclerotiorum. Plant Pathol. 2015;64:101-8.

Wei JL, Huang LL, Gao ZP, Ke XW, Kang ZS. Laboratory evaluation methods of apple Valsa canker disease caused by Valsa ceratosperma sensu Kobayashi. Acta Phytopathol Sin. 2010;40:14-20 (in Chinese). http://zwblxb.magtech. com.cn/CN/.

Wong FP, Wilcox WF. Distribution of baseline sensitivities to azoxystrobin among isolates of Plasmopara viticola. Plant Dis. 2000;84:275-81.

Zang R, Huang LL, Kang ZS, Wang XL. Biological characteristics and pathogenicity of different isolates of Cytospora spp. isolated from apple trees in Shaanxi province. Acta Phytopathol Sin. 2007;37(4):343-51 (in Chinese). http://zwblxb. magtech.com.cn/CN/

Zhang XK, Wu DX, Duan YB, Ge CY, Wang JX, Zhou MG, et al. Biological characteristics and resistance analysis of the novel fungicide SYP-1620 against Botrytis cinerea. Pestic Biochem Physiol. 2014;114:72-8.

Zhang Y, Lu JL, Wang JX, Zhou MG, Chen CJ. Baseline sensitivity and resistance risk assessmemt of Rhizoctonia cerealis to thifluzamide, a succinate dehydrogenase inhibitor. Pestic Biochem Physiol. 2015;124:97-102.

Ziogas BN, Markoglou AN, Malandrakis AA. Studies on the inherent resistance risk to fenhexamid in Botrytis cinerea. Eur J Plant Pathol. 2003;109:311-7.

\section{Ready to submit your research? Choose BMC and benefit from:}

- fast, convenient online submission

- thorough peer review by experienced researchers in your field

- rapid publication on acceptance

- support for research data, including large and complex data types

- gold Open Access which fosters wider collaboration and increased citations

- maximum visibility for your research: over $100 \mathrm{M}$ website views per year

At BMC, research is always in progress.

Learn more biomedcentral.com/submissions 